\title{
ABC of mental health Mental health and the law
}

Ann Barker

The law relating to medical practice in general, and mental health in particular, is complex. This article provides a summary of the laws applying in England and Wales. Certain mental disorders are the only medical conditions for which the law permits treatment without the consent of the patient, but this can be undertaken only in a hospital or registered nursing home.

\section{Mental Health Act 1983}

Most treatment of mental disorder is undertaken voluntarily, whether in the community or on an outpatient basis or during a hospital stay. Compulsory admission of a patient from the community must be for one or more legal reasons set out in the Mental Health Act. Admission for assessment or treatment of a patient with a mental disorder may be necessary for the patient's health, the patient's safety, protection of others, or all of these.

Section 2 of the act allows for compulsory admission for assessment (and subsequent treatment), while section 3 allows for compulsory treatment when the category of mental disorder is already determined. These sections require recommendations from two doctors, one of whom is "approved" under section 12 of the act and one-usually the patient's general practitionerwho has knowledge of the patient. An application for admission is usually made by an approved social worker, but in certain circumstances the patient's nearest relative may fulfil this role.

The legal categories of mental disorder are mental illness, psychopathic disorder, and mental impairment, and the mental disorder must be so severe as to warrant treatment in hospital rather than in the community. The definitions of psychopathic disorder and mental impairment include a disorder of behaviour. In addition, both categories must be considered treatable before admission to hospital is warranted. An important role of the patient's social worker is to ensure that resorting to hospital treatment is made only when necessary.

\section{Emergency admission}

Sections 4 and 5 of the Mental Health Act permit emergency admissions. When there is "urgent necessity" one doctor, preferably with previous knowledge of the patient, and a social worker or the nearest relative may compel admission under section 4 . It is good practice that use of this section be converted to section 2 by recourse to an approved doctor.

If the patient is already an inpatient-but not an outpatient or someone attending an accident and emergency department-he or she may be prevented from leaving hospital by one doctor under section 5(2). If the doctor in charge of treatment is not a psychiatrist (for example, an obstetrician), he or she must act in person (not by proxy) and make immediate contact with a psychiatrist. A patient receiving treatment for both physical and mental conditions should be detained by the consultant psychiatrist or his or her nominated deputy.

\section{Treating detained patients}

In an emergency, treatment can be given under common law in the best interests of the patient. Only longer periods of detention, which involve assessment by two doctors, allow for

\section{Legal pathways to compulsory treatment or care}

\section{Mental Health Act 1983}

Section 2,3, or 4-Admission to hospital from the community

Section 5-Detained by a nurse or a doctor while already an inpatient

Section 35, 36, 37, 38, or 41-Admission on the authority of a court after an offence

Section 47 or 48-Admission from prison on Home Office authority Section 135-Taken by police from a private dwelling under a magistrate's warrant

Section 136-Taken by police from a public place to a place of safety

National Assistance Act 1948

Removal to suitable premises of people in need of care and attention

Powers of Criminal Courts Act 1973

Treatment as a condition of a probation order

Legal authority exists for supervision in the community but not for compulsory treatment (including drug treatment)

\section{Legal categories of mental disorder}

Mental illness-Not specified

Psychopathic disorder-A persistent disorder of mind (not specified) resulting in abnormally aggressive or seriously irresponsible conduct

Mental impairment and severe mental impairment-Arrested or incomplete development of mind with considerable or severe impairment of intelligence and impaired social functioning and abnormally aggressive or seriously irresponsible conduct

General guide to arranging compulsory admission from the community (local arrangements may vary)

Agencies involved

- General practitioner (or other doctor with prior knowledge of the patient)

- Doctor approved under section 12 (consultant psychiatrist for catchment area, doctor from local community mental health centre, or "on call" psychiatrist)

- Social worker approved under the act

Coordination

- The agency coordinating the assessment is usually decided by local agreement

- Involves arranging a time and place for the assessment, identifying a hospital bed, supplying legal documents (section papers), and arranging transport (such as an ambulance) and escort (doctor, community nurse, social worker, or police)

Urgency

- Attempt to judge the urgency of the situation in terms of safety and wellbeing of the patient and other people

- In emergency consider admission under section 4

Access (if patient will not grant access or submit to assessment)

- Try persuasion-Patient's general practitioner, community psychiatric nurse, relatives, or close friends may be able to persuade the patient

- In exceptional cases the social worker may apply to a magistrate for a warrant to force entry under section 135

Safety

- Do not act alone-Consider safety of the patient, staff, and others

- Should the police be asked to attend?

- Allow plenty of time-Most patients can be persuaded to cooperate if given enough time 
medical treatment for mental disorder to be administered forcibly. However, electroconvulsive therapy may not be given to detained patients without their consent unless permission is obtained from the Mental Health Act Commission.

A detained patient's consent to psychiatric treatment must be reviewed after three months, and, if he or she does not consent, permission to continue treatment must be sought from a "second opinion approved doctor" appointed by the Mental Health Act Commission.

\section{Treatment after a criminal offence}

Of the six million criminal offences notified to the police each year, the vast majority are minor property offences, such as shoplifting, and are dealt with in magistrates' courts. Some 100000 serious offences (such as homicide, grievous bodily harm, arson, and rape) proceed to the Crown Court.

Hospital orders-Either court may pass a hospital order under section 37 of the Mental Health Act for inpatient treatment when there is evidence of mental disorder, but only the Crown Court may make a hospital order under section 41, which allows the Home Office to place restrictions on a patient's movements. Patients under this order may be recalled to hospital if, for example, they do not take their medication in the community.

Probation orders-Outpatient treatment may be undertaken under a probation order with a condition of psychiatric treatment, provided that the patient agrees. Probation officers fulfil the role of social worker, and, in the event of a patient not complying with the conditions, he or she may be returned to court for an alternative sanction.

\section{National Assistance Act 1948}

Section 47 of this act allows for patients to be removed from their dwelling place to suitable premises, most often hospital, if they fulfil all the following conditions:

- They are living in insanitary conditions

- They are suffering from serious chronic disease or are aged or infirm or are physically incapacitated

- They are not receiving proper care and attention.

The doctor-usually a public health physician-makes a report to this effect, which then requires approval from the local court.

\section{Consent to treatment}

All treatment proposed by a doctor must be in the best interests of the patient. It is, however, a patient's right to give or withhold consent to examination or treatment. Procedures undertaken without consent can (though rarely) lead to an action for damages or a criminal prosecution for assault.

Consent may be implied, such as when a patient offers an arm for venepuncture, or expressed in oral or written form. Written consent is often necessary, but it is the explanation by the doctor that is paramount. Over the age of 16 , only the patient can legally give consent, but the agreement of a close relative is sensible when it is impossible to gain consent from the patient.

When treatment for a physical disorder is necessary and the patient seems mentally disordered, a psychiatrist should be consulted to confirm the presence of mental disorder and the treatment of the medical condition be undertaken in the best interests of the patient. Mental incapacity includes dementia and mental handicap and may include other mental disorders. No one can give consent on behalf of these patients, but it is wise to seek the views of close relatives and to take a second

\section{Welfare of detained patients}

The rights of detained patients are overseen by two separate bodies, the Mental Health Review Tribunals and the Mental Health Act Commission

\section{Mental Health Act Commission}

- Oversees the welfare of patients detained in hospital and publishes a Code of Practice for their treatment, the authority of which is analogous to that of the Highway Code for motorists

Address-Maid Marian House, 56 Houndsgate, Nottingham NG1 6BG Telephone 01159504040.

\section{Mental Health Review Tribunals}

- Have the legal authority to release a patient from hospital if they consider that his or her mental disorder is not sufficiently severe, or that the risk to his or her own health or safety or the safety of others is not sufficiently great, to justify continued detention

- All patients detained in hospital for longer than 72 hours have the right to a tribunal hearing to argue the legality of their detention, and also the right to be legally represented at the hearing (including legal aid)

- There are three regional tribunals in England and one in Wales

\section{Detention and treatment for the protection of others}

- A "tiered" approach may be necessary for assessing the risk of harm to others: first dealing with immediate issues of safety and security and then assessing the continuing risks

- Risk implies uncertainty, and an attempt at accuracy requires great attention to detail

- It is important to assess the amount and type of harm predicted and the likelihood of this harm occurring, from "no risk" to "very high risk"

How much information do you have?

- As much information as possible should be sought from, for example, relatives, neighbours, probation officers, and even local newspaper reports

What kind of danger do you anticipate?

- Is it likely that the patient will steal from shops, hit his or her partner, or take a knife and stab a stranger in the street?

How likely is it to happen?

- Where and under what circumstances is it likely that dangerous behaviour will occur?

- Does the patient always carry a knife, meet the potential victim every day at work, at football matches, or only at Christmas?

What could change to alter the risk?

- Dangerousness is never static but is a dynamic state that varies with mental health and variations in daily circumstances

Some predictors of danger to others

- History of violence or sexual assaults • Young, male

- Misuse of alcohol or drugs - "Feels out of control"

- Stops medication for major mental illness

Suicide by mentally disordered patients is much more common than homicide, but patients should be asked as routinely about thoughts of harming others as they are asked about suicidal thoughts

Mentally disordered patients can be capable of consenting to treatments, both for their mental disorder and for physical disorders

\section{The best interests of the patient}

This is treatment that is

- Accepted by a responsible body of medical opinion

- Designed to save life, ensure improvement, or prevent deterioration of physical or mental health 
consultant opinion. For irreversible procedures (such as sterilisation or amputation) permission should be sought from the Family Division of the High Court. Unconscious patients are incapable of giving consent and should be treated for life threatening disorders unless there is prior expressed evidence that the patient did not wish the treatment.

Children aged under 16 years who are able to understand their suggested treatment may give valid consent that cannot be reversed by their parents. If a child refuses the treatment it may still go ahead if the parents consent. For a child subject to a care order, the opinion of the local authority overrides parental consent. The doctor's paramount duty is to treat the child, and refusal by the parents should be noted in the clinical record. Girls aged under 16 may be provided with contraceptive advice or termination of pregnancy without parental consent if they forbid the doctor to seek it and the treatment is in their best interests.

Patients may give restricted consent (for example, Jehovah's Witnesses' refusal to permit blood transfusions), and a note should be made of the precise restriction made. A patient's choice of treatment may be overruled by an application to the Family Division of the High Court. A doctor can refuse to treat only if there is another doctor available to undertake treatment or if no harm will ensue.

\section{Confidentiality}

All members of a healthcare team should be aware of the duty of confidentiality, and case notes should be kept secured. A breach of professional confidentiality is viewed seriously by the General Medical Council. Information may be divulged with the patient's consent, preferably in writing, or on instruction from his or her solicitor, who is assumed to convey that consent. After a patient's death, permission should be sought from the executor of his or her estate.

Difficulty commonly arises when a patient is in breach of the law. Wherever possible the doctor should attempt to gain the patient's consent to give information, or obtain a request from the court to submit a report. The doctor may breach confidentiality on the grounds of public interest if "the failure to disclose appropriate information would expose the patient, or someone else, to a risk of death or serious harm" but should be able to justify the decision. If in doubt, the doctor should consult his or her defence society.

\section{Access to Health Records Act 1990}

A health record relates to the physical or mental health of a patient, written by almost any professional except a social worker or teacher. Patients may read, have a copy, and have an explanation of their record. They may also apply to have their record corrected if they consider it inaccurate: in response, a correction may be made or the objection noted. Records made before 1 November 1991 are accessible only if necessary to make the later record intelligible.

Information about psychiatric patients is commonly given in confidence by relatives or carers, and divulging this information may put them at risk from the patient. In such cases parts of the medical record may be withheld from the patient.

Ann Barker is consultant forensic psychiatrist, The Bracton Centre, Oxleas NHS Trust, Bexley, Kent.

The ABC of mental health is edited by Teifion Davies, senior lecturer in community psychiatry, United Medical and Dental Schools, St Thomas's Hospital, London, and honorary consultant psychiatrist, Lambeth Healthcare NHS Trust, and T K J Craig, professor of community psychiatry, United Medical and Dental Schools, St Thomas's Hospital.

\section{A valid consent to treatment requires a full explanation in non-technical language of the nature and purpose of the procedure to a patient capable of understanding the explanation and such explanation of the material risks that is reasonable in the circumstances by an appropriately qualified clinician for the particular procedure proposed on an ongoing basis without unfair or undue pressure}

\section{Difficulties in gaining consent}

- Mental disorder

- Mental incapacity

- Children

- Restricted consent

"I will respect the secrets which are confided in me, even after the patient has died"

Declaration of Geneva 1947

\section{Grounds for breaching patient confidentiality}

Legal duty to release information

- Certain infectious diseases

- Registration of births and deaths

- Children at risk

- Misuse of illegal drugs

- Termination of pregnancy

- Prevention of terrorism

Duty to comply with a request for information

- Report to a judge or chairman of a court

- Report to a coroner

- Release of medical record to police on order of a circuit judge

- Name and address to police in a road traffic offence

\section{Access to medical records}

A patient's request for access to his or her medical records should be respected Access may be restricted, or some information withheld, if

- The information is likely to cause serious harm to the mental or physical health of the patient

- The information is likely to cause serious harm to the mental or physical health of another person (not including health professionals)

- The information is about, or provided by, another individual (again not a health professional)

\section{Further reading}

Managing self-harm: the legal issues. Drug Ther Bull 1997;35:41-3 British Medical Association. Rights and responsibilities of doctors. 2nd ed. London: BMJ Publishing, 1992

British Medical Association, the Law Society. Assessment of mental capacity: guidance for doctors and lawyers. London: BMA, 1995

Davies T. Consent to treatment. Psychiatr Bull 1997;21:200-1

Department of Health, Welsh Office. Code of practice. Mental health act 1983. London: HMSO, 1993

Jones R. Mental health act manual. 5th ed. London: Sweet and Maxwell, 1996 